\title{
Investigating of Mechanical Behavior of AA5083 in the Pressing Process Using Finite Element Analysis
}

\author{
Babak Beglarzadeh ${ }^{1} \&$ Behnam Davoodi $^{2}$ \\ ${ }^{1}$ Department of Mechanical Engineering, Science and Research branch, Islamic Azad university, Tehran, Iran \\ ${ }^{2}$ School of Mechanical Engineering, Iran University of Science and Technology, Tehran, Iran \\ Correspondence: Babak Beglarzadeh, Department of Mechanical Engineering, Science and Research branch, \\ Islamic Azad University, Tehran, Iran. E-mail: Babak.Beglarzadeh@gmail.com
}

Received: July 10, 2017

Accepted: July 16, 2017

Online Published: August 21, 2017

doi:10.5539/mas.v11n9p51

URL: https://doi.org/10.5539/mas.v11n9p51

\begin{abstract}
The process of cold forming is considered of the most different industries and the use of such process in the manufacture of components and small parts has expanded. Therefore, analyzing the behavior of metals in this process to identify and control durability that is the main factor of limiting process has particular importance in industrial forming processes. In this study, cold forming process of aluminum metal has been studied and its effect on its mechanical properties has been evaluated. For this purpose, first modeling piece of aluminum alloy 5083 for cold forming process is carried out and using finite element analysis, mechanical properties of considered piece during cold forming processes are investigated. The results show that by reducing friction, stress and strain during the process will reduce, thereby durability of the piece increases, or in other words, ductile fracture occurs in longer life and higher stresses. The results show that by proper forming operations, it can be improved the strength and durability of aluminum alloy. Finally, validation of results, by comparing simulation results with experimental results is carried out.
\end{abstract}

Keywords: aluminum alloy 5083, forming, mechanical properties, finite element analysis

\section{Introduction}

Aluminum alloys due to low weight and high corrosion resistance are considered in various industries. Today, the cold pressing forming processes in the production of industrial parts such as automotive, aircraft and so on have many applications. It is noteworthy that in many processes of forming, deformation based on pressure operations is performed. The important part is in the metal forming analysis to model the collision and friction between the material and the form at the intersection of mold and metal. Friction plays an important role in all processes of metalworking, exist friction between the mold and the workpiece in the process of cold pressing of upsetting directly involved in plastic deformation of piece when a solid sample is compressed between two plates, contact surface friction causes to delay (prevent) of the free flow of material and the tapered edges are formed of the metal almost non- deformed that at the bottom of the cylinder remain. And the deformation parts under the effect of high strain difficulty in the middle parts of sample are focused. That as bulges towards the outside are placed, however, in practice, the use of lubricants reduces the degree of barreling.

Simulation of metal forming process includes geometric parameters (geometry of the tool and workpiece) process (moving of tool and mold, temperature, friction) and material (hard work, the ratio of hardness of strain). Information that can be obtained from the simulation of process, including material flow and details of swelling mold, predicting imperfections of flow such as folds / laps, the distribution of strains, strain rate and stress in materials, pressure distribution between the mold and material and impact of mechanical properties such as friction. Forming process simulation to evaluate materials geometric changes as nonlinear is necessary. During the past decade, several numerical techniques to understand the theory of large plastic deformation as well as solve nonlinear problems have developed. It is considered that the finite element method is a reliable way to such issues.

Upsetting cold compression test is used to determine the workability to use in designing large forming processes (Kuhn, 1988). In this experiment, a cylindrical sample between two parallel and flat jaws is squeezed. Often to obtain surface flow stress and fraction of free surface, this experiment is performed on samples with ratio of height to different initial diameter and under different lubrication conditions (Kobayashi, Oh \& Altan, 1989; Harris, 1983). 
Free surface of samples by different methods become network and measuring the change of network dimensions beside deformation is used to obtain the fraction locus (Ferdinand, Petr \& Michal, 2015; (Zhao, Song, Yan, Zhang,\& Pei, 2016; Feng, Chen, Qiang \& Wang, 2016).

Friction has severe effect on the workability of the material. For example, in a process that lubrication conditions is right, the inhomogeneous deformation is minimized, while if lubrication conditions is not appropriate, sharp shear bands are formed in the material. The effect of friction on network deviations in direct extrusion is shown in Figure 1 (Breadly \& Yilong, 1987; Giardini, Cerreti \& Maccarini, 1995; Lee \& Altan, 1972). Figure (a) 1 shows the deformation in low friction, figures $(b, c) 1$ show the effect of increasing wall friction on the sample flow. In Figure (c) 1, there are long wide shear zones or bands, but in the figure (b) 1 shear bands are limited to areas adjacent dead metal (Breadly \& Yilong, 1987).

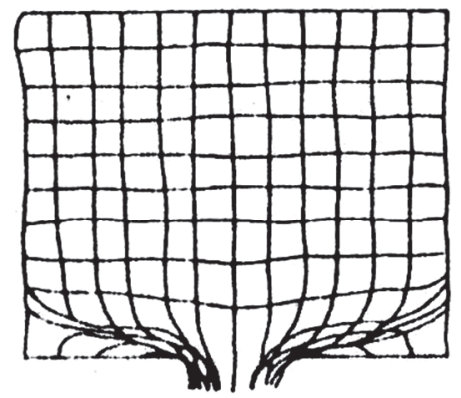

(a)

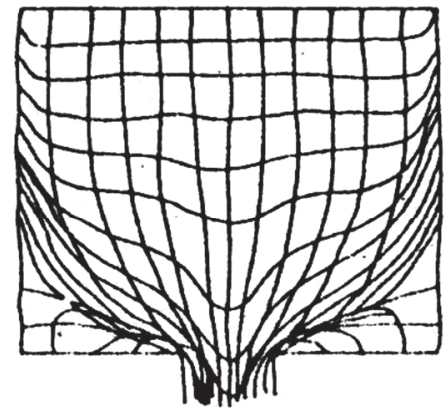

(b)

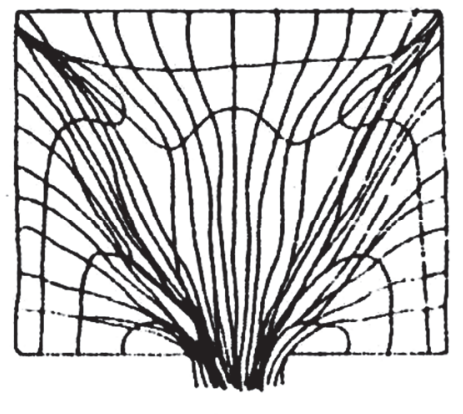

(c)

Figure 1. Kinds of deformation in direct extrusion in conditions, (a) low friction, (b) Medium friction and (c) high friction (Breadly \& Yilong, 1987)

Obvious defects produced by various metalworking processes create a useful and easy method for estimating the workability of materials. Kinds of defects and metal processes based on process type, by Johnson and Mamalis (Kobayashi, 1970) are divided. Cook and Lark (Cook \& Lark, 1945) pressured samples with ratio of height to different initial diameter to a certain strain. Then drew tension observed, $\sigma_{\text {obs }}$, to the $\mathrm{D}_{0} / \mathrm{H}_{0}$. Prediction for $\mathrm{D}_{0} /$ $\mathrm{H}_{0}=0$ shows compressive yield stress to strain applied.

In this study, for stimulation of upsetting cold press process, finite element method and using ANSYS software is used. Then the effect cold forming on mechanical properties of aluminum during the process is examined. Finally, numerical results using the finite element with experimental results are verified.

\section{Research Methodology}

\subsection{Upsetting Cold Pressure Test of Cylindrical Samples}

One of the most common and simplest tests of workability is the upsetting compression test. This test is used to evaluate the actual stress-stress curve of materials (Hartley, Sturgess \& Rowe, 1980). In this experiment, there is friction that causes barreling. The analysis of many forming processes requires knowing the yield stress pressure. This stress must be corrected for friction that this reform could be done as analytical or experimental.

To analyze the cold working processes, the Coulomb stress $\tau=\mu \mathrm{N}$ is used where $\mathrm{T}$ is friction stress (shear), $\mu$ is the coefficient of friction and $\mathrm{N}$ is the normal stress. Since in most processes, $\mu$ is constant, rarely depends on variables such as material properties, lubrication, and strain rate (Pohlanddt, 1989). In upsetting cold compression test, modify barreling is influenced by sample dimensions and used lubricant. The use of concentric grooves on both ends of the sample with the use of Teflon sheet with proper thickness as lubricant minimizes barreling.

Singh and Padmanabhan (Singh \& Padmanabhan, 1982) conducted pressure test on aluminum samples with constant strain rate. During the test in a constant strain drew curve $(\mathrm{D} / \mathrm{H})-\sigma_{\mathrm{obs}}$. The results are shown in Figure 2. Of the curve, compressive yield stress of aluminum is obtained by cutting $\mathrm{Y}$ axis. By using this value, slope, $\mu$ is calculated. For $\mathrm{Al}$, the value of $\mu$ in all strains was equal 0.15 that the amount was independent of strain rate and piece size. 

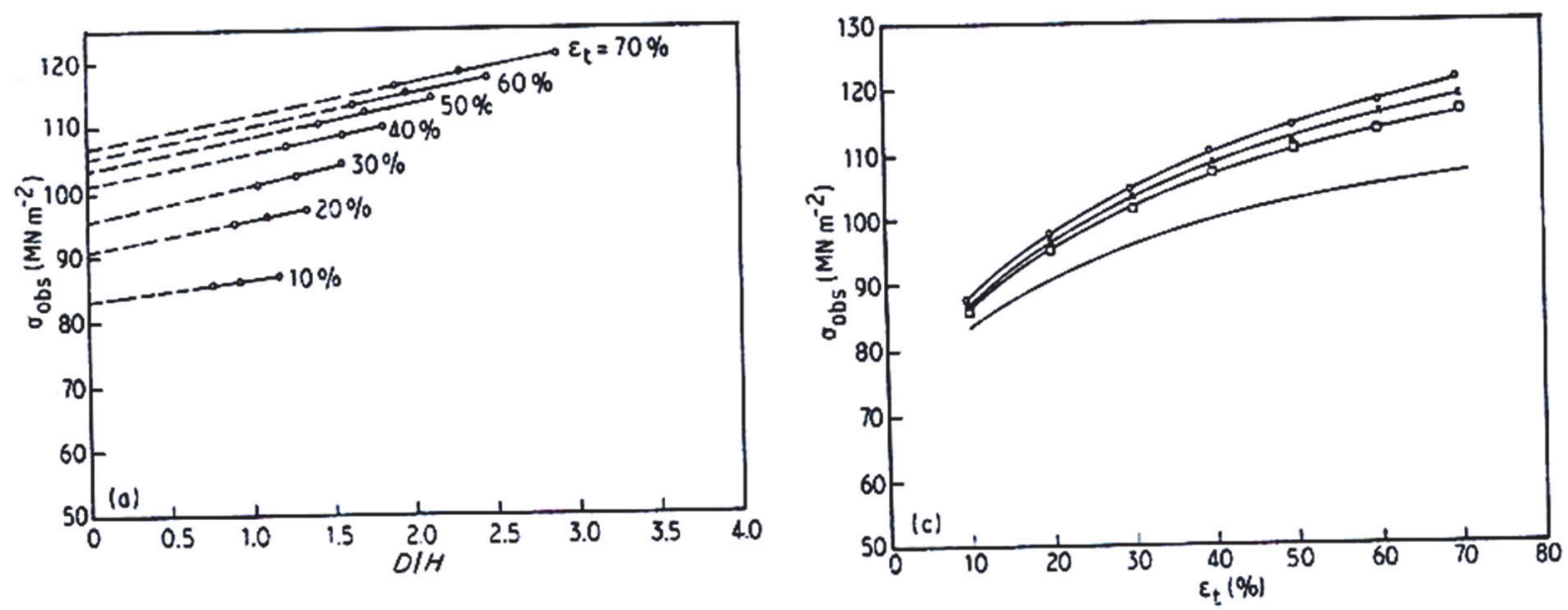

Figure 2. Actual compressive stress observed, relationship (H / D) бobs at room temperature at different percentages of true strain for aluminum business with initial strain rate of $8.2 \times 10$ and size of $50 \mu \mathrm{m}$ (Singh \&

Padmanabhan, 1982)

\subsection{Strain Instability and Fraction at the Surface of Pressure Cylinders}

to study fraction using the compression test, measuring axial and environmental strains in the equatorial plane of the bulge level is required. This measurement can be done on measure signs in the middle height of the sample which is shown schematically in Figure 3. Initial tests have shown that the ring strain is around the uniform axis and can be determined as shown in Figure (3) from the equatorial diameter. Researchers have usually utilized Vickers hardness indentations or gridlines engraved on the surface as a gauge for measuring strains. However, these techniques cause to stress concentration. Kuhn and Lee (Samanta, 1975) in order to eliminate this effect in their experiments created stripes of measure by placing two cellophane rough stripes with interval $0.076 \mathrm{~cm}$ and separately at middle altitude of sample and by sprinkling blue color (color of comparison of dimensions). When the stripes have been removed, stripe of measure obtained with sharp edges (Figure 4).

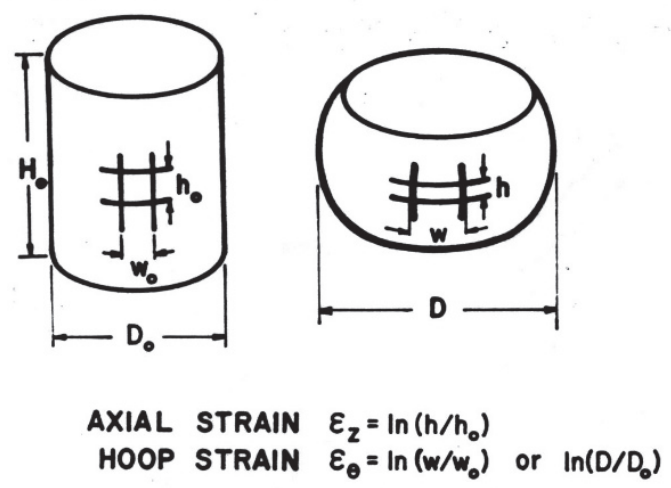

Figure 3. Schematic of the networks published in the press test to measure strains (Kuhn \& Lee, 1971)

In (Kuhn \& Lee, 1971) conducted their experiments under friction conditions (1) rough molds (ribbed surfaces),

(2) polished molds with payment ${ }_{\mathrm{m}} \mu$ and (3) polished molds with lubricants (graphite in calcium base grease

that before each stage of deformation was used.) on AISI 1045 steel samples and with ratios of height to different initial diameter from 0.75 to 1.75 .

The results of measuring strain compression test are shown in Figure 4. In this form, axial and environmental strains are presented as a function of altitude strain. In the early stages of stress, strains increase uniformly, then suddenly reach to flat position and remain stationary until by increasing hoop strain again increase and this 
increasing is done with the same ring strain. After further deformation, fraction in the bulge and at $45^{\circ}$ to the axis becomes apparent. For condition obtained a different friction and ratios of height with similare diameter. Figure 5 shows the effect of friction conditions to the strain perturbation, $\left(\varepsilon_{Z}-\right.$ over $\left.\varepsilon_{\theta}\right)$. Since the perturbation occurs in all friction conditions, this perturbation cannot be attributed to the change of friction condition from slip to complete adhesion. Kuhn and Lee repeated tests again using network lines engraved with distance $0.076 \mathrm{~cm}$ and obtained unique results that indicate that strain perturbation observed is not due to color layers used in stripe measure, but probably is a response from the substance (Kuhn \& Lee, 1971).

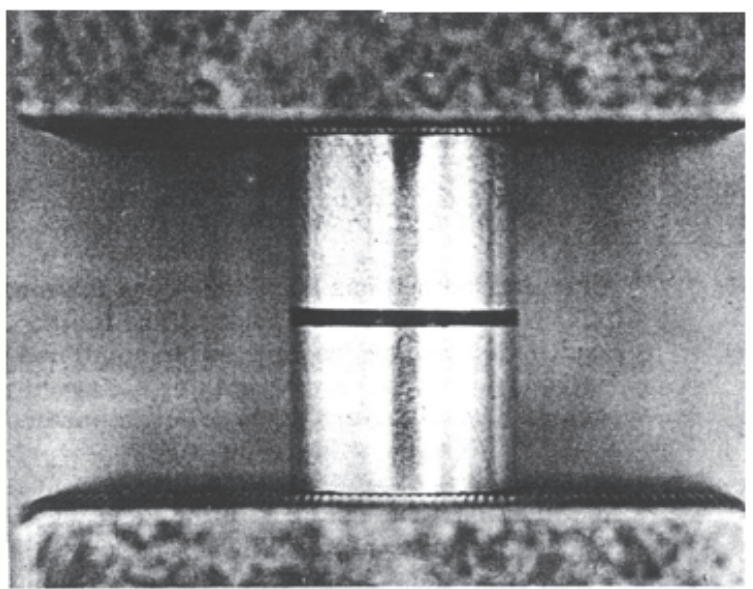

(a)

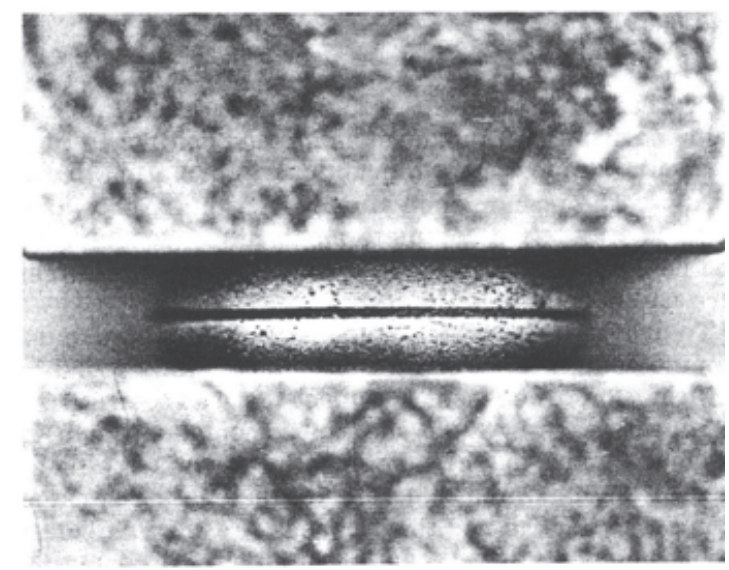

(b)

Figure 4. Stripes of measure to measure axial strain on pressure cylinders (a) before test and (b) after the test with magnification $\times 2($ Kuhn $\&$ Lee, 1971)

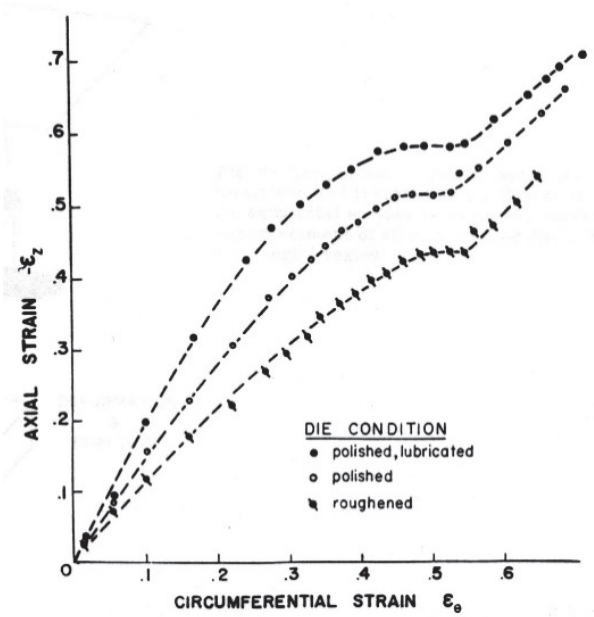

Figure 6. Axial strain $\left(\varepsilon_{\mathrm{Z}}\right)$ to the environmental strain $\left(\varepsilon_{\theta}\right)$ for pressure cylinders $\frac{H_{\circ}}{D_{\circ}}=1.5$, three friction conditions and stripe of measure 0.03 (Kuhn \& Lee, 1971).

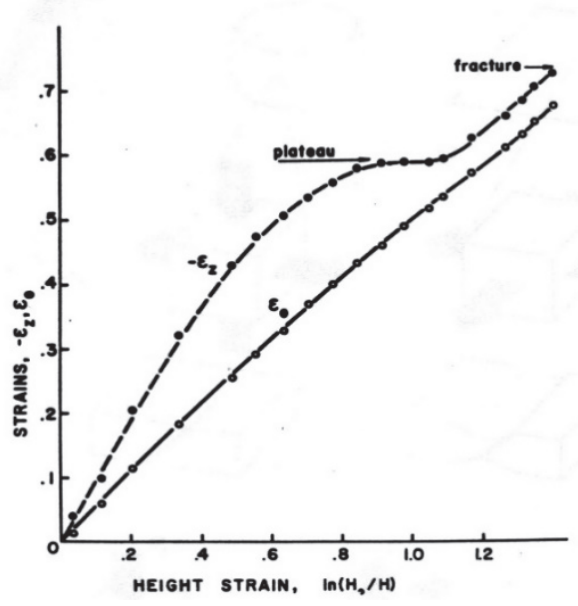

Figure 5. Axial strain curve $\left(\varepsilon_{\mathrm{z}}\right)$ and environmental strain $\left(\varepsilon_{\theta}\right)$ to height strain for pressure cylinders, represents a deviation of strain for $\frac{H_{\circ}}{D_{\circ}}=1.5$ and the stripe of measure 0.03 (Kuhn \&

Lee, 1971). 
Kuhn and Lee to test these possibilities conducted several test with strips of measure $0.33 \mathrm{~cm}$ and 0.076 on the same material. Figure 7 shows the measured strain on the stripe of measure $0.33 \mathrm{~cm}$ uniformly during the test increases, while the strain measured on the stripe measure $0.076 \mathrm{~cm}$, shows in axial strain of flat mode (Kuhn \& Lee, 1971).
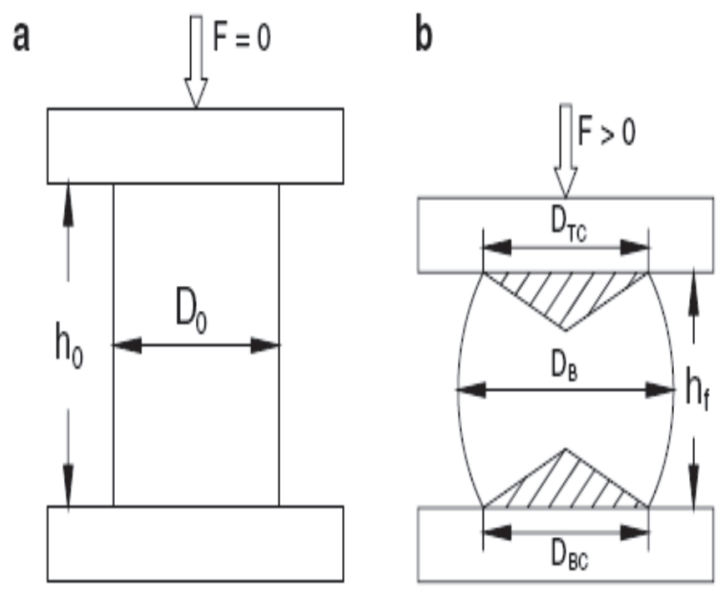

Figure 8. Sample of before and after deformation (Kuhn $\&$ Lee, 1971)

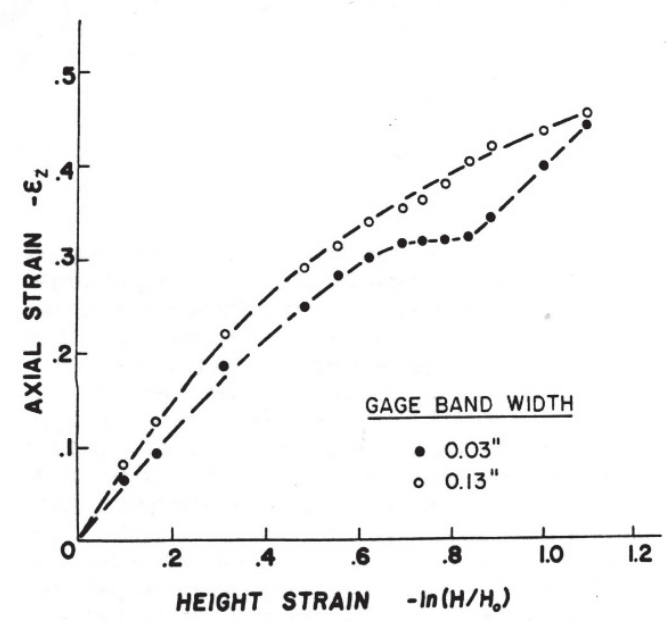

Figure 7. Axial strain versus the environmental strain

\subsection{Material and Model Used}

The material used is aluminum 5083 which has chemical composition and mechanical properties of below.

Table 1. Chemical composition of aluminum (Thiyaneshwaran, Sureshkumar \& Mechanical, 2013) 5083

\begin{tabular}{|c|c|c|c|c|c|c|c|c|c|c|c|}
\hline $\mathrm{Al}$ & $\mathrm{Si}$ & $\mathrm{Fe}$ & $\mathrm{Cu}$ & $\mathrm{Mn}$ & $\mathrm{Mg}$ & $\mathrm{Cr}$ & $\mathrm{Ni}$ & $\mathrm{Zn}$ & $\mathrm{Ti}$ & $\mathrm{Be}$ & $\mathrm{Ca}$ \\
\hline Base & 0.05 & 0.26 & 0.01 & 0.56 & 4.80 & 0.08 & 0.01 & 0.03 & 0.02 & $<0.001$ & $<0.001$ \\
\hline $\mathrm{Li}$ & $\mathrm{Pb}$ & $\mathrm{Sn}$ & $\mathrm{Sr}$ & $\mathrm{V}$ & $\mathrm{Na}$ & $\mathrm{Bi}$ & $\mathrm{C}$ & $\mathrm{Zr}$ & $\mathrm{B}$ & $\mathrm{Ga}$ & $\mathrm{Cd}$ \\
\hline$<0.001$ & $<0.001$ & $<0.002$ & $<0.001$ & 0.01 & 0.005 & $<0.004$ & 0.004 & $<0.001$ & 0.003 & 0.01 & $<0.001$ \\
\hline
\end{tabular}

Table 2. Mechanical properties of aluminum 5083 (Thiyaneshwaran, Sureshkumar \& Mechanical, 2013)

\begin{tabular}{ll}
\hline Tensile strength & $145 \mathrm{MPa} \equiv 21000 \mathrm{psi} \quad$ AA; Typical \\
\hline Compressive modulus & $71.7 \mathrm{GPa} \equiv \_10400 \mathrm{ksi}$ \\
Poisson's ratio (Estimated similar alloys) & 0.33 \\
\hline
\end{tabular}

\subsection{Impact of Extrusion on Mechanical Properties of Aluminum}

In the following the impact of aluminum 5083 extrusion process on mechanical properties such as hardness, stress and friction is provided.

\subsubsection{Impact of Extrusion on Hardness}

Figure (9) shows the impact of aluminum 5083 extrusion on the micro hardness of Vickers alloy. It is observed that after forming, Vickers hardness in the first stage increases from HV 105 to HV142 and in the second stage, forming increases with a less slope from HV142 to HV 141. Increasing micro hardness is due to homogenization and improvement of infrastructure of alloy respectively. 


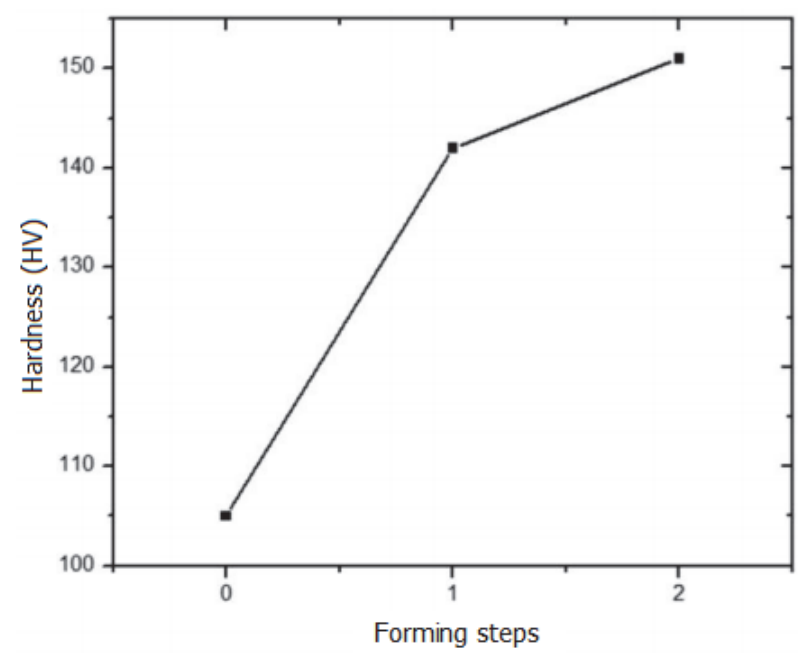

Figure 9. The impact of forming stages on changes of micro hardiness of aluminum alloy 5083

\subsubsection{Characteristics of Stress}

Changes of Aluminum 5083 alloy stress due to the forming in table (3) are provided. The bending strength and final stretch of alloy before cold forming respectively is 342 and $390 \mathrm{Mpa}$ and with strain 25 percent. After forming YS, $29 \%$ increase and in the amount of $397 \mathrm{Mpa}$, the maximum stretch, and strain, respectively, $18 \%$ and $16 \%$ increase. The results show that forming metal by monitoring alloy pieces reduces resistance to fracture of piece.

Table 3. The impact of forming stages Aluminum 5083 alloy resistance

\begin{tabular}{ccc}
\hline YS $(\mathrm{MPa})$ & UTS $(\mathrm{MPa})$ & Elongation to failure $(\%)$ \\
\hline 309 & 342 & 25 \\
397 & 404 & 16 \\
441 & 447 & 15 \\
\hline
\end{tabular}

\subsubsection{Friction Properties}

Figure 10 shows the impact of load on mass loss in aluminum alloy and without forming. The results show that mass loss and friction with increasing load, in both cases increases. Sample of forming shows friction and more mass loss than the original mode.

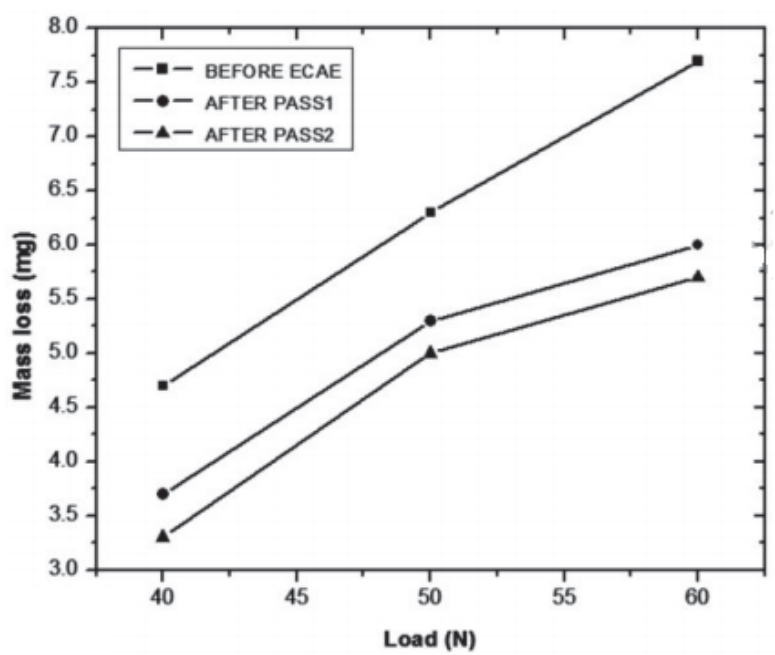

Figure 10. Impact of load on friction of aluminum alloy 


\section{Simulation}

The samples simulated have a diameter of $19 \mathrm{~mm}$ and heights of 28.5 and 19 and $9.5 \mathrm{~mm}$ with a length to diameter ratio $1.5,1,0.5$. Mold is assumed two jaws of pressure devise that the lower jaw is fix and upper jaw squeezes the upper sample at a constant speed between the two.

Table 4. Coefficient of friction and the compressive yield stress of aluminum 5083. (Thiyaneshwaran, Sureshkumar \& Mechanical, 2013)

\begin{tabular}{|c|c|c|c|c|c|c|c|}
\hline $\begin{array}{l}\boldsymbol{\varepsilon} \\
0.1\end{array}$ & $\begin{array}{l}\sigma_{0}(\mathrm{MPa}) \\
177.14\end{array}$ & \multicolumn{3}{|l|}{$\boldsymbol{\sigma o b s}$} & \multicolumn{3}{|l|}{$\boldsymbol{\mu}$} \\
\hline $\begin{array}{l}0.1 \\
0.2 \\
0.3 \\
0.4\end{array}$ & $\begin{array}{l}177.14 \\
203.07 \\
215.07 \\
221.42\end{array}$ & $\begin{array}{l}=\mathbf{1} / \mathbf{5} \mathrm{D}_{0} / \mathrm{H}_{0} \\
180.01 \\
206.66 \\
220.84 \\
230.07\end{array}$ & $\begin{array}{l}=\mathbf{1} / \mathbf{0} \mathrm{D}_{0} / \mathrm{H}_{0} \\
181.44 \\
208.46 \\
223.73 \\
234.39\end{array}$ & $\begin{array}{l}=\mathbf{0} / \mathbf{5} \mathrm{D}_{0} / \mathrm{H}_{0} \\
185.74 \\
213.86 \\
232.38 \\
247.36\end{array}$ & $\begin{array}{l}=\mathbf{1} / \mathbf{5} \mathrm{D}_{0} / \mathrm{H}_{0} \\
0.072 \\
0.081 \\
0.12 \\
0.177\end{array}$ & $\begin{array}{l}=\mathbf{1} / \mathbf{0} \mathrm{D}_{0} / \mathrm{H}_{0} \\
0.072 \\
0.081 \\
0.12 \\
0.177\end{array}$ & $\begin{array}{l}=\mathbf{0} / \mathbf{5} \mathrm{D}_{0} / \mathrm{H}_{0} \\
0.072 \\
0.081 \\
0.12 \\
0.177\end{array}$ \\
\hline
\end{tabular}

\subsection{Results of a Study on the Ductility of Metals in Upsetting Cold Pressing Process}

In Figure 11 is shown simulated curves of cylindrical samples after deformation for three ratios of height to different initial diameter $(0.5,1,1.5)$ with strain 0.3 in the state of non-lubrication. It should be noted that in the forms, plastic strain (plastic-strain) in the case of Von Mises plastic strain is shown.

As can be seen from the figure, the greatest deformation has occurred in the bulging area for each three ratio. Homogeneity deformation in the samples has not occurred and samples as bulging (a barrel) are deformed. Most deformation is related to ratio of $\mathrm{H} / \mathrm{D}=0.5$ with a value of 0.454666 . The maximum deformation for ratio $\mathrm{H} / \mathrm{D}$ $=1.5,0.406448$ and for the ratio $\mathrm{H} / \mathrm{D}=1.0$ is equal to 0.431299 .

In Figure 12 is shown simulated curves of cylindrical samples after deformation for three ratios of height to different initial diameter $(0.5,1,1.5)$ with strain 0.3 in the state of non-lubrication. It should be noted that samples as homogeneous have deformed and barreling phenomenon has not happened.

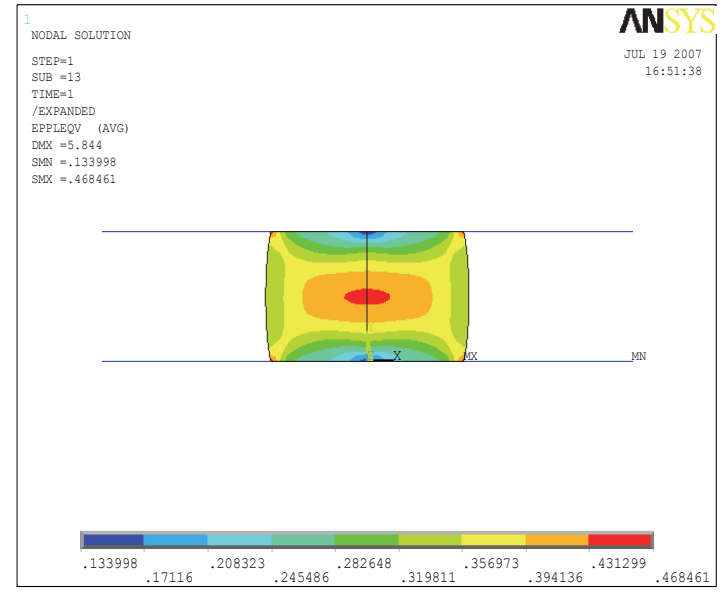

(b)

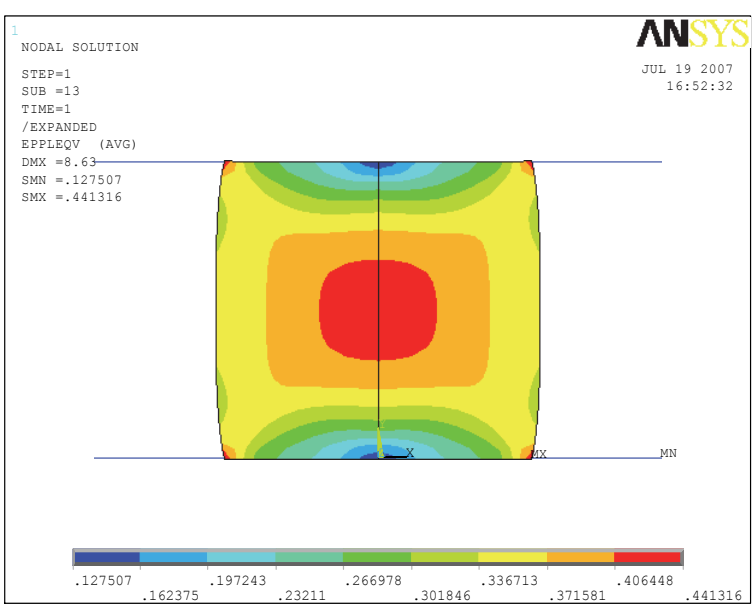

(a) 


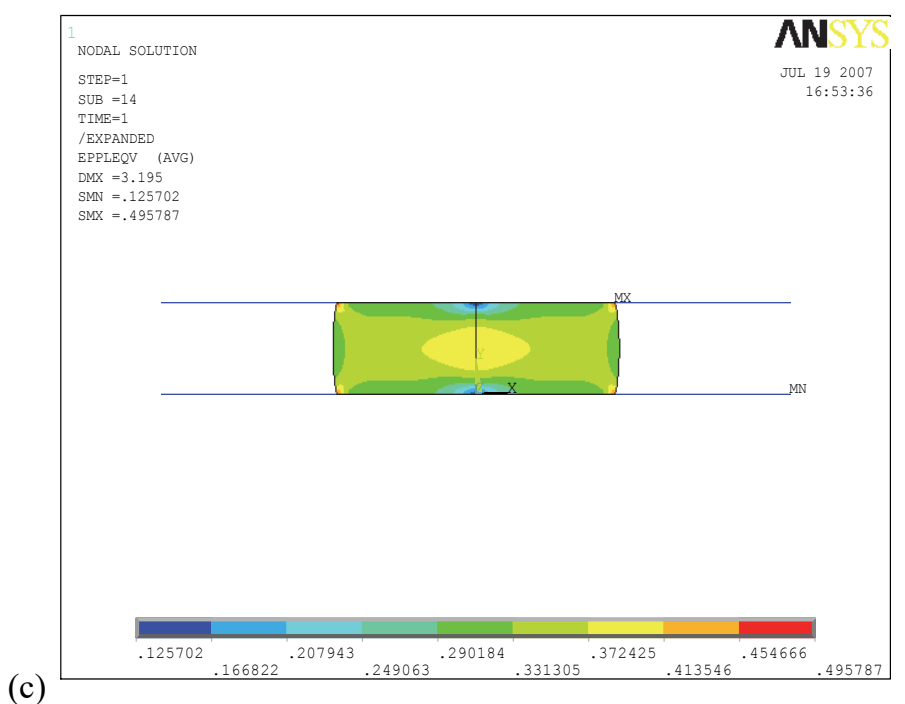

Figure 11. Simulated curves of samples of cylindrical shape after deformation to strain 0.3 and the coefficient of friction $\mu=0.12$ (a). $\mathrm{H} / \mathrm{D}=1.5$, (b) $\mathrm{H} / \mathrm{D}=1.0$ and (c) $\mathrm{H} / \mathrm{D}=0.5$

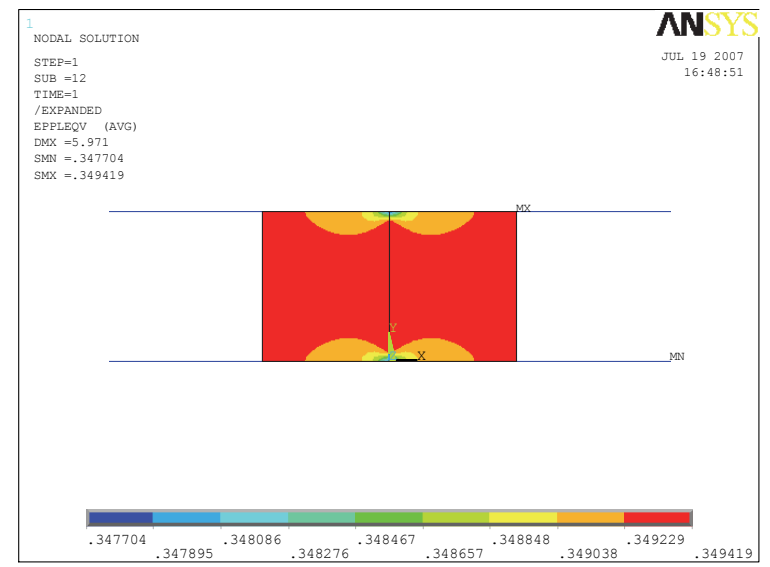

(b)

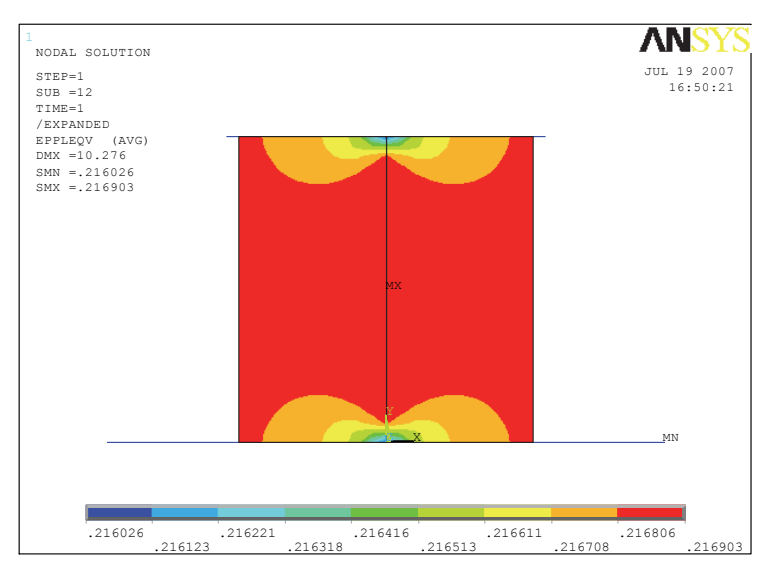

(a)

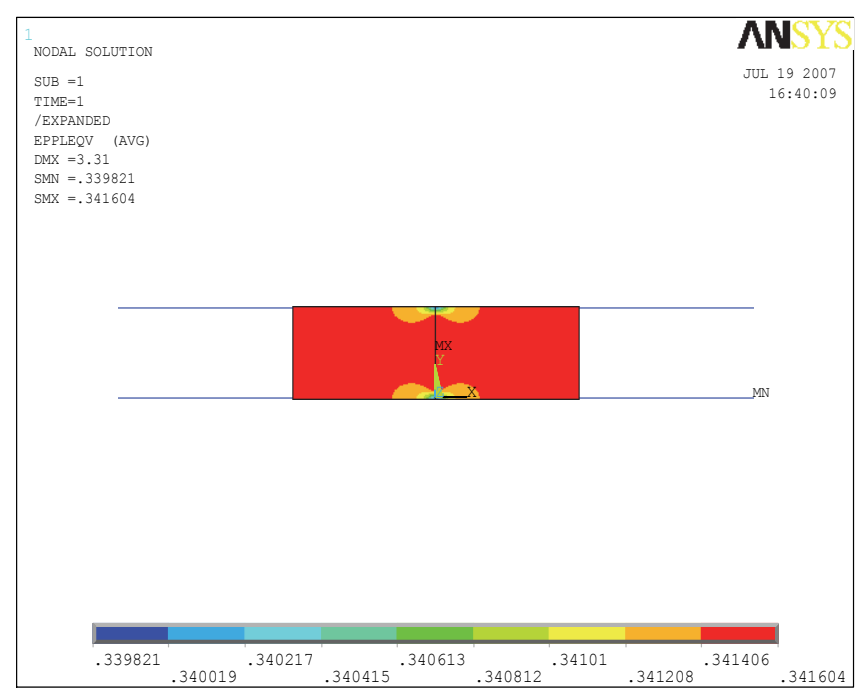

(c)

Figure 12. Deformed cylinders to strain in lubricated condition $(\mu=0.0)$ to state $(\mathrm{a}) \mathrm{H} / \mathrm{D}=1.5$, (b) H / D = 1.0 and (c) $\mathrm{H} / \mathrm{D}=0.5$ 


\subsection{Study the Effect of Processing Parameters on Formability of Aluminum in the Process of Upsetting Cold Pressing}

In the pressure test with increasing strain, the contact surface of samples pressure plates increases. By increasing the surface area and reducing lubricant material, shear stresses caused by the friction at the contact surface gradually increases. The creation of radial and environmental stresses due to friction in the opposite direction of flow causes to increase forces required for deformation determined.

\subsection{Barreling Study in the Process of Upsetting Cold Pressure Process}

The impact of friction and the ratio of height to initial diameter of the sample on the barreling of cylinders samples of aluminum is shown in Figures 11 and 12.

As can be seen in the figures 11 and 12, aluminum samples in per three ratios of height to initial diameter of the sample under lubrication conditions not become barreling and are uniformly deformed. According to Figure 11 can be seen that for the case without lubrication, barreling occurred and its severity is increased by reducing the ratio of height to initial diameter of sample.

According to the forms, 11 and 12 can be seen that by reducing the height to initial diameter ratio, the size of the lateral area and dead area increases, as well as the difference between the maximum and minimum strain on the material increases. Therefore, by reducing H/D the strain heterogeneity increases. As a result of the heterogeneity of deformation by reducing H/D the proportion increases. Thus, the numerical and empirical experiments done (Thiyaneshwaran, Sureshkumar \& Mechanical, 2013; Ramezani et al., 2006) the same results are obtained and the results of numerical experiments confirmed by empirical experiments.

\section{Conclusion}

1. In case of lubricated, sample is uniformly deformed and remain as cylinder while in conditions without the use of lubricant, deformation is non-uniform shape and will focus on barreling area.

2. In terms without lubricated, due to focus of deformation in barreling area, stress required for a certain strain deformation is more than required strain for deformation of lubricated sample.

3. Mechanical properties such as stress resistant and micro-hardness of aluminum alloy 5083 by cold forming, by informing piece of structure and homogenizing it, increases.

4. Forming process of aluminum alloy increases the mass loss and friction of alloy during industrial applications.

5. Studies conducted on ANSYS finite element software through problem solving of upsetting cold pressure test show that by reducing the height to initial diameter ratio of sample, the size of the lateral area and dead area increases, as well as the difference between the highest and the lowest created in the material increases. Therefore, experimental and numerical experiments show the same results for heterogeneous deformation.

\section{References}

Breadly, D., \& Yilong, B. (1987). Ductile Fracture and Ductility with Applications to Metalworking", 1st ed., Academic Press, London.

Cook, M., \& Lark, E. C. (1945). Resistance of copper alloys to homogeneous deformation in compression. Journal of Institute Metals, 71, 371-390.

Feng, Y. H., Chen, J. H., Qiang, W., \& Wang, K. H. (2016). Microstructure and mechanical properties of aluminium alloy 7A52 thick plates welded by robotic double-sided coaxial GTAW process, Materials Science and Engineering: A, In Press.

Ferdinand, D., Petr, D., \& Michal, B. (2015). Estimation of the mechanical properties of aluminium and an aluminium composite after equal channel angular pressing by means of the small punch test. Materials Science and Engineering: A, 626, 313-321.

Giardini, C., Cerreti, E., \& Maccarini, G. (1995). Formability in extrusion forging: the influence of die geometry and friction conditions. Journal of Materials Processing Technology, 54, 302-308.

Harris, J. N. (1983). Mechanical Working of Metals Theory and Practice. Pergamon Press, Oxford.

Hartley, P., Sturgess, C. E. N., \& Rowe, G. W. (1980). Influence of friction on the prediction of forces, pressure distributions, and properties in upset forging. International Journal of Mechanical Sciences, 22, 743-753.

Kobayashi, S. (1970). Deformation characteristics and ductile fracture of 1040 steel in simple upsetting of solid cylinders and rings. Journal of Engineering for Industry, 391-399.

Kobayashi, S., Oh, S. I., \& Altan, T. (1989). Metal Forming and the Finite-Element Method. Oxford University 
Press, New York.

Kuhn, H. A. (1988). Workability Theory and Application in Bulk Forming Processes. Metals Handbook, 9th ed., $14,388-404$.

Kuhn, H. A., \& Lee, P. W. (1971). Strain instability and fracture at the surface of upset cylinders. Metallurgical Transactions, 2, 3197-3202.

Lee, C. H., \& Altan, T. (1972). Influence of flow stress and friction upon metal flow in upset forging of rings and cylinders. Journal of Engineering for Industry, 775-782.

Pohlanddt, K. (1989). Materials Testing for the Metal Forming Industry. Translated R. Kuehl, Springer-Verlag, Berlin.

Ramezani, A. et al. (2006). Study deformation of metals in the process of upsetting cold pressure. Tehran University.

Samanta, S. K. (1975). On the limit of plastic deformation in compression of circular cylinders. International Journal of Fracture, 11, 301-313.

Singh, A. P., \& Padmanabhan, K. A. (1982). Surface contours in the axi-symmetric upsetting of solid cylinders. Journal of Materials Science, 17, 821-831.

Thiyaneshwaran, N., Sureshkumar, P., \& Mechanical, M. (2013). Wear Properties Of Aluminum 5083 Alloy Processed By Equal Channel Angular Extrusion. International Journal of Engineering Research \& Technology (IJERT), 2, 17-22.

Zhao, Y., Song, B. Y., Yan, Z. Y., Zhang, X., \& Pei, J. Y. (2016). Microstructure and mechanical properties of extrusion welds in continuous extrusion of AA6063 aluminium alloy with double billets. Journal of Materials Processing Technology, 235, 149-157.

\section{Copyrights}

Copyright for this article is retained by the author(s), with first publication rights granted to the journal.

This is an open-access article distributed under the terms and conditions of the Creative Commons Attribution license (http://creativecommons.org/licenses/by/4.0/). 